\title{
Assessment of Beef Transportation Infrastructure from Slaughtering Facilities in Tanzanian Cities
}

\author{
Joseph Tenson Mwashiuya'1, Samwel Victor Manyele², George Mwaluko \\ ${ }^{1}$ Department of Mechanical and Industrial Engineering, University of Dar es Salaam, Dar es Salaam, Tanzania \\ ${ }^{2}$ Department of Chemical and Mining Engineering, University of Dar es Salaam, Dar es Salaam, Tanzania \\ Email: joseftenson@yahoo.com, smanyele@udsm.ac.tz,mwalukogeorge@yahoo.com
}

How to cite this paper: Mwashiuya, J.T., Manyele, S.V. and Mwaluko, G. (2018) Assessment of Beef Transportation Infrastructure from Slaughtering Facilities in Tanzanian Cities. Engineering, 10, 814-836. https://doi.org/10.4236/eng.2018.1011057

Received: October 22, 2018

Accepted: November 26, 2018

Published: November 29, 2018

Copyright (๑) 2018 by authors and Scientific Research Publishing Inc. This work is licensed under the Creative Commons Attribution-NonCommercial International License (CC BY-NC 4.0). http://creativecommons.org/licenses/by-nc/4.0/

\section{(c) (i) \& Open Access}

\begin{abstract}
This study presents the assessment of beef transportation infrastructure from slaughtering facilities in Tanzanian cities to the retail premises. The quality of beef consumed in many countries is questionable due to poor infrastructural development which may results into contamination and bacteriological infection. This study was carried out in Mbeya and Dar es Salaam where data was collected at the dispatch areas of 3 and 6 slaughtering facilities, respectively. At each slaughter facility, 10 vehicles selected randomly, were assessed. The assessment of beef distribution infrastructure was conducted based on 18 quality impacting factors established from the actual observation and literature review and conceptualized carcass distribution model. With exception to water tightness, painting and engine status during carcass loading, all the assessed beef quality impacting parameters were below 50\%, indicating that beef distribution in the surveyed facilities were below the specification of food quality. Generally, the assessment of beef transporting facilities in connection to the first hypothesis of this study, indicted very weak compliance with the requirements, signifying that the vehicles are not acceptable for carcass transportation.
\end{abstract}

\section{Keywords}

Slaughtering Facilities, Beef Transportation Infrastructure, Beef Quality Impacting Parameters, Compliance Index, Likert Statement, Beef Retailing Premises

\section{Introduction}

Infrastructural development in connection to road and meat transporting ve- 
hicles is one of the main components of beef quality management challenges facing the post-slaughter animal handling in Tanzania [1] [2] [3] [4]. Postslaughter animal handling begins at the abattoir (just after killing), and continues to processers of meat (processing meat into various meat products), to the market (selling of meats) and finally to consumers (cooking and eating) [4] [5]. This paper focuses on transportation from the abattoir to the sell-point. Many developing countries are characterized by poor infrastructural development in meat sector, thus the quality of beef consumed in these countries is questionable [1] [2] [4]. This questionability is described based on possibilities of contamination and bacteriological infection in beef due to three main scenarios. The first one is the distribution in non-appropriately transporting vehicles through poorly maintained roads [1] [5] [6]. Secondly, transportation of beef processed from cattle that were slaughtered at night or early in the morning under inappropriately illumination [1]. Lastly, inappropriate cold chain management as beef is processed, transported and sold without refrigeration and or temperature controlling [2] [4]. Therefore, in this regards the transported carcass undergoes various poorly managed handling processes post-slaughter which have adverse effect on meat quality [7].

The factors studied and which affect the beef quality include distribution vehicles' status (painting, labelling, carcass carrying compartments design features), conditions of carcass dispatching area at the slaughtering facilities, drivers and attendants adherence to the sanitary conditions, etc. [2] [4] [6]. Furthermore, the study includes statistical analysis for compliance data for beef distributing facilities by analysis of variance (ANOVA). The study will provide knowledge and skills to the key players involved in maintaining beef quality as it is transported from slaughtering facilities to sell points or butchers. While other studies presented challenges in the transportation of meat, this study focuses on beef transportation only.

The whole beef supply chain is designed based on the processes along the slaughtering, distribution and beef retailing points and finally preparation and consumption. Information on beef quality was collected at a key segment of the supply chain that distributed from slaughtering facilities. The conceptualized scheme formulated in this study includes population groups of the study, i.e., cities (Mbeya and Dar es Salaam), slaughtering facilities, carcasses transporting vehicles, beef retailing shops and consumers. This paper focuses on one item, i.e., carcass transportation infrastructure and how it affects beef quality after slaughter processes until reaches the retailing shops. These population groups were identified from vague and general idea of beef quality management. Therefore, within the listed types of population, samples were drawn as per beef distributing vehicles departing from slaughtering facilities.

In this study, the identified problem affecting beef quality was the poor transportation infrastructure. This problem was addressed by testing two main hypotheses, namely, the beef transporting infrastructure in the Tanzanian cities does not comply with the food quality specification, and the level of compliance 
with respect to beef transportation infrastructure in different cities is significantly different.

\section{Literature Review}

\subsection{Challenges Facing Beef Supply Chain}

Meat products belong to the group of perishable foodstuffs which get spoiled faster when kept in wrong environment [6]. Meat is prone to natural, continuous and irreversible bio-physiochemical changes (high water content, the presence of protein, carbohydrates and fat promote the processes of oxidation and rancidity) [3] [8]. To ensure the health and safety of meat products, it is required to use suitable raw material, appropriately selected cooling methods (freezing), the storage and distribution conditions and a continuous monitoring and control, in accordance with the applicable quality assurance systems [9] [10] [11]. The process of transport, especially of meat products, should be subjected to a special surveillance system in accordance with the applicable system for hazard analysis and determination of critical control points (HACCP) which is weakly regulated in Tanzania. Chilled or deep-frozen foodstuffs are subject to the procedure of maintaining unchanged conditions in which they have to be kept (cold chain) [5] [6] [12]. This means that from production, transport and distribution until the consumption by consumers, both the chilled and frozen products should be stored at an appropriate temperature [6] [11]. In this study, the vehicles transporting beef were assessed on whether beef is exposed to environmental contaminants or not and it required temperature during transportation are attained. Exposing beef to conditions outside the range of recommended temperatures, in either of the links of the cold chain, can result in lowering the quality, as well as changes which may impact the health security [5] [6] [12]. In the cold chain, there are many critical points at which its continuity can be interrupted [9].

Unless otherwise, post-mortem inspection must be followed immediately by chilling in the slaughtering facility to ensure a temperature throughout the meat of not more than $3^{\circ} \mathrm{C}$ for offal and $7^{\circ} \mathrm{C}$ for other meat along a chilling curve that ensures a continuous decrease of temperature [6]. During the chilling operations, there must be adequate ventilation to prevent condensation on the surface of the meat [5]. Meat must attain the specified temperature before transport, and remain at that temperature during transportation [5] [6].

\subsection{Post-Slaughter Handling of Beef}

After slaughter, the colour of meat depends on a principal pigment, myoglobin, which when mixed with oxygen becomes oxymyoglobin, and produces a bright red colour [13]. Therefore, during distribution the accumulation of air must be avoided as this pigment depends on the oxygen status of the environment. Literature shows that poor handling of meat during transportation may result in a high rate of contamination and spoilage [3] [4] [6] [14]. When transporting 
meat, the challenge is to maintain proper refrigeration temperatures and keep the cold chain from breaking during steps such as palletization, staging, loading and unloading of containers, and in storage [6] [15]. The cold chain must not be interrupted as bacteria multiply rapidly in higher temperatures [3] [4] [6] [12] [15]. The temperature and handling conditions must be strictly adhered to in all stages of the cold chain, through properly designed handling procedures in the chilled storage rooms [6].

\subsection{Characteristics of Meat Vans for Beef Transportation}

The vehicles used to transport meat from abattoir to retail meat outlets may act as sources of contamination due to reported observation that the vehicles often lack regular cleanliness and are not well covered leading to contamination by dusts, insects and flies [3] [4] [6]. Contamination of meat resulting from other means of transport such as motor-bikes and bicycles has also been reported due to insufficient vans and trucks [4]. On the other hand, lack of transport facilities and the fact that the available vehicles are not properly cleaned leads to observed contained high microbial loads [3].

The different points of transport, from cold storage to the retail outlet, and then to the consumer refrigerator, are critical points for the beefs overall quality and safety [6]. A significant factor is the temperature inside the transport vehicles, and the fluctuations occurring during transit. The vehicle must be provided with a good refrigerated system, operating constantly during transportation to maintain properly chilled conditions. Another important issue is to avoid undesirable heat infiltration, which may occur due to hot weather, sunny conditions, inadequate insulation or air leakage. When taking precautions to avoid the above, it should be possible to achieve the recommended optimal conditions.

Legislation on control of transport equipment and temperatures during beef transportation has been increasingly stricter, especially for intra-European transports of refrigerated foods. Within the beef transport process one of the weakest links in the distribution chain is the transport period either the abattoir to the butcher or from the retailing shop to the consumer domestic refrigerator. There are limited published data quantifying the former parameter.

\subsection{Beef Storage during Transportation}

\subsubsection{Previous Research on Beef Transportation}

Studies in area of beef transportation infrastructure in connection to the quality management have been conducted in both developing and developed countries. Some of these studies were focused in beef quality management specifically on the assessment of the compliance of beef transportation with respect to handling against the quality impacting factors. Although several methods for assessing the compliance with the specification of meat transportation have been used in literature, their respective findings were in general statement rather than specific level of compliance criteria. The findings in most of these studies were presented 
in terms proportion and or percentage of the units, i.e., the units that were not adhere to the sanitation and hygiene standards. For, example, while the literature [4], indicated $58 \%$ and $27 \%$ of the beef transporting vehicles in Nairobi and Isiolo counties in Kenya adhered to the specification of using the closed meat carrying compartment, other studies [16] indicated the cumulated $55 \%$ of the transporting facilities worked as per beef transportation requirements in Colombia. Furthermore, the study in beef transportation in Juba town, South Sudan indicated that $80 \%$ and $68.57 \%$ of the assessed vehicles were distributing beef contrary to the requirement in open vehicles to kiosks and butchers, respectively. Other studies on the other hand indicated the application of a dynamic Temperature Function Integration (TFI) model as a justifiable criterion of the management of refrigeration during the post-slaughter carcasses handling [17]. TFI is currently used for both quantifying the compliance of processes and adequacy of new processes based on the good manufacturing process (GMP) [17] [18].

\subsubsection{Previous Research on Beef Transportation}

This research is based on the compliance index based model that was used in [19] [20] to assess the compliance with disclosure requirements of the statement of accounting standard (SAS) and international accounting standard (IAS) requirements. For, example, the model was applied in finance management during which, [19] [20], assess the compliance with the requirements with the specifications based on five graded levels, i.e., strongly applied (70\% - 100\%), semistrongly applied (50\% - 69\%), weakly applied $(40 \%-49 \%)$, very weakly applied (20\% - 39\%), and non-application (0\% - 19\%). The study involved eleven variables in SAS requirements and 21 in IAS. The technique was also used in medical discipline, when, literature [21], predicted the treatment compliance and development of pleural effusions in elderly patients with chronic myeloid leukemia treated with second line dasatinib. In this study, evaluation was conducted based on Charlson Commodity Index (CCI) that has a list of 19 conditions (each condition has a weight assigned from 1 to 6 , derived from relative risk estimates of proportional hazard regression model using clinical data). ANOVA as a tool for analysis on the other hand, is a collection of statistical models and their associated estimation procedures used to analyze the differences among group means in a sample.

\section{Methodology}

\subsection{Carcasses Distributing Conceptual Model}

Factors that influencing the quality of beef in during distribution were established from the actual observation and literature review technical requirement based on the conceptualized slaughtering model as shown in Figure 1. This is a model that is designed based on information on beef quality technical requirement and the gap observed in actual situation. The conceptual model expresses 


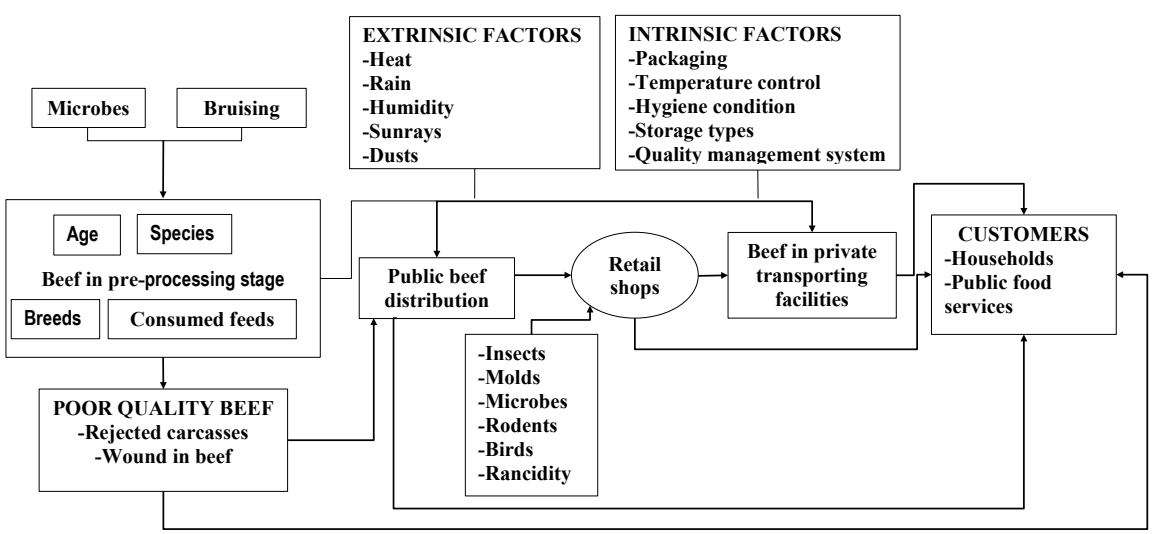

Figure 1. Conceptualized model that indicates beef quality impacting factors during beef transportation to retailing shops (designed based on literature [3] [5] [6]).

the detail of the study areas on the carcasses distributing vehicles specifically on the impact of both infrastructural features and the respective processes to the beef quality. This model was developed from a total of 32 main components.

\subsection{Assessment Checklist for Carcasses Distributing Vehicles}

The beef retailing assessment checklist was designed based on the described conceptual model as shown in Figure 1. The model includes features that were further detailed to beef quality impacting factors for the beef distributing vehicles. This resulted into a checklist with a total of 18 compliance requirements to be assessed in the form of positively and negatively worded items, i.e., Likert items as indicated in Table 1.

\subsection{Study Area}

The study was carried out in Mbeya and Dar es Salaam and conducted based on the established hypotheses along the beef supply chain between January and April 2017. According to 2012 population and housing census, as the Dar es Salaam city with a total area of $1800 \mathrm{~km}^{2}$ has a population of 4.36 million in 2012 United Republic of Tanzania (URT), Mbeya city with $19,098 \mathrm{~km}^{2}$ has a population of 0.69 million. Dar es Salaam and Mbeya cities are characterized by high level of poverty despite the various efforts on interventions. Among other poverty indicators, the difficultness for their respective residents on accessing the basic needs in 2011 was at 5.2\% and 24.3\% levels, respectively [22]. As Dar es Salaam has six slaughter facilities with capacity to slaughter 720 cattle a day, Mbeya has three slaughtering facilities with daily capacity of 200 cattle [23]. The stock that is slaughtered in these cities is distributed to butchers that are classified based on income class of the clientele into high, middle, low and extra-low levels. During the study, data that is connected to beef quality management were collected from carcasses distributing vehicles found at slaughtering facilities. In Mbeya, data was specifically collected from three slaughtering facilities, i.e., Ilemi, Uyole and Mbalizi that were purposely pointed as they being the only registered facilities around that location. 
Table 1. Beef quality impacting parameters in the checklists used for data collection during assessment of beef distributing vehicles.

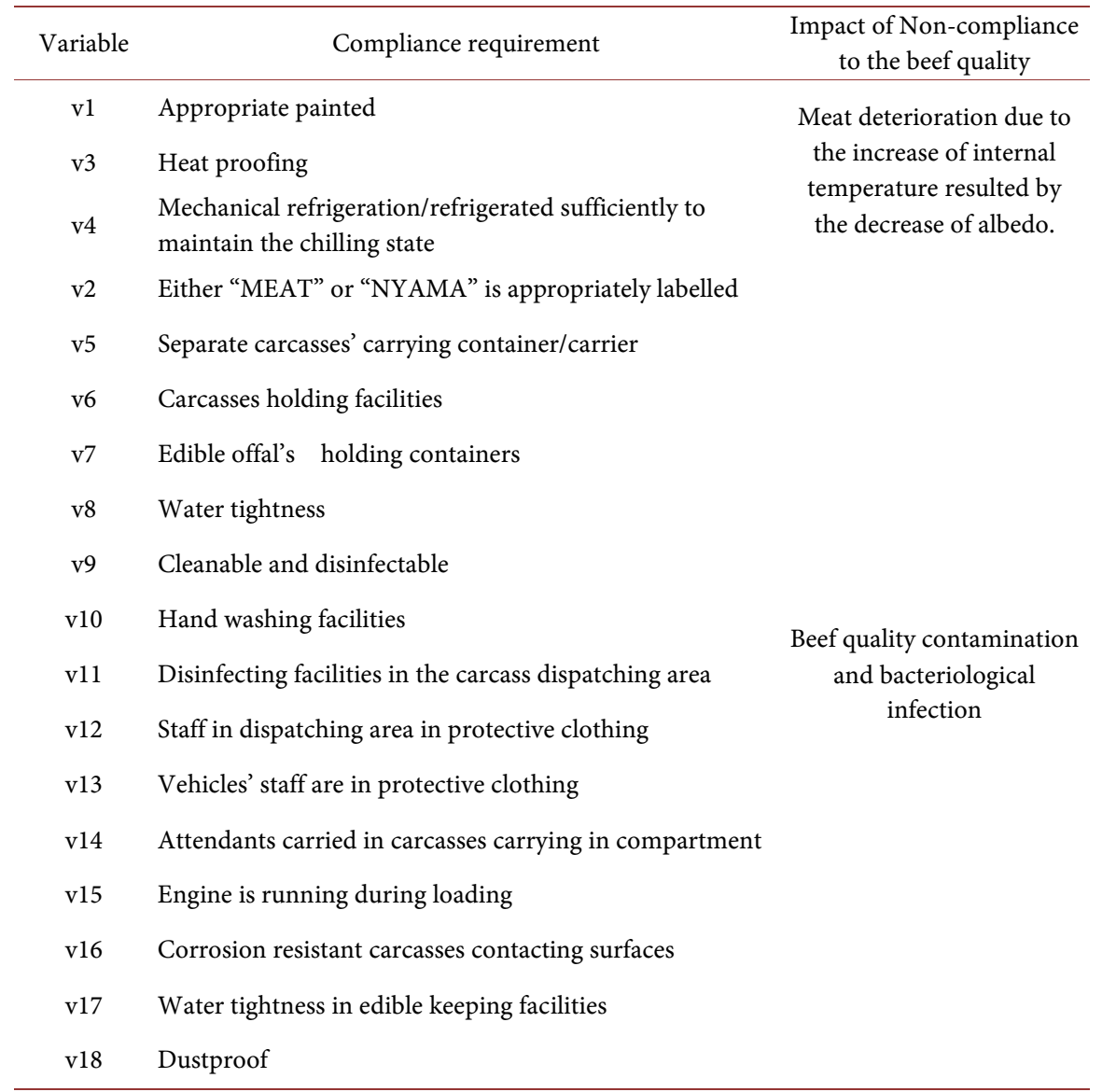

Dar es Salaam city was selected because of its unusually high population due to its metropolitan characteristics which attract many people looking for employment in the industries [22]. Mbeya city was also targeted due to the availability of consumers from working that includes government departments, Institutions, private companies and entrepreneurs [24]. In addition, these cities were chosen as study areas as they have direct access to other countries through Julius Nyerere and Songwe International Airports, respectively, being potential for export of meat from Tanzania.

\subsection{Data Collection Techniques}

This assessment study involved data collection through observation of the beef quality impacting parameters in the beef distribution infrastructure by using a structured checklist. The gathered data were then analyzed by using the spread sheet with respect to the objective and statistical hypotheses established. The checklists were designed for recording the scored points on the responses on the Likert statement based on the food requirements on transportation. It is empirical study that was designed based on the gaps identified by the past work against the similar problem, and have not yet been examined [10]. The designing was 
carried out to purposively identify beef transporting facilities in the conveniently selected slaughtering facilities. In connection to that, Dar es Salaam and Mbeya cities were purposively selected based on the reflection of the potential market of beef in connection to both general population and their respective exporting international airports.

\subsection{Statistical Analysis Techniques}

Data was statistically analyzed by using a compliance index and Analysis of Variance (ANOVA) based models. Compliance index based technique was applied in various studies to assess the compliance with quality management specifications. It was conducted based on condition graded levels (each condition weighted based on the assigned specific number of categories) from a given estimates.

Based on this information, together with the specification, the beef quality impacting parameters from the identified Likert items were analyzed. The total compliance indices were constructed by comparing the infrastructural requirements for beef quality management against data gathered along the beef distribution chain only. Each of the listed requirements was given a unique number, for instance, $v_{i},(i=1,2, \cdots, 18)$ indicating requirement number one and so on. As in the past studies, on compliance to the requirement [19] [20], this study adopts an ascending scoring system at $0,0.25,0.50$, and 1 compliance levels. The parameters that should be addressed on handling of beef quality management along the chain were assessed against 18 requirements developed based on the criteria. The criterion set used, provides the decision rule to which the computed compliance index lead to acceptance or rejection of the hypotheses developed in this study. All the entities with compliance indices less than $20 \%$ were excluded from the population sampled.

\section{Results and Discussion}

\subsection{Characteristics of the Carcasses Distributing Vehicles}

Result on the evaluated beef distributing vehicles conducted at different slaughtering facilities is presented based on FAO standards on food quality. It is presented under assumption that painting, labeling, carrying compartment and carcasses contacting surfaces in the distributing facilities are the key beef quality judgment criteria. The detailed analysis of vehicle characterization involved four main categories, namely, as to whether it was appropriately painted in white and red strip; availability of the word "meat" and or the Swahili translated "Nyama"; degree of separateness of the carcasses carrying compartment; and the nature of the carcasses contacting surfaces as to whether it was corrosion resistant or not.

Figure 2 shows the total scores for the four categories in which the compiled scores of the responses on the evaluated, painting of vehicles, labeling information, degree of separateness, and corrosion free surfaces on carcasses distributing vehicles were assessed on 10 vehicles per slaughter house. Compliance of the 


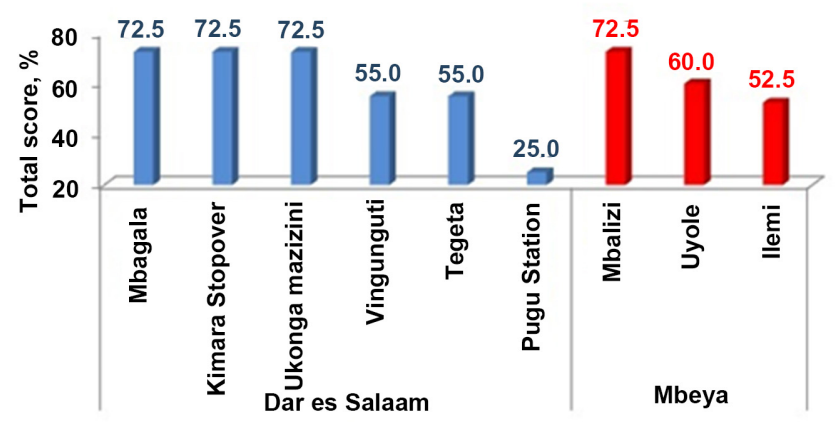

(a)

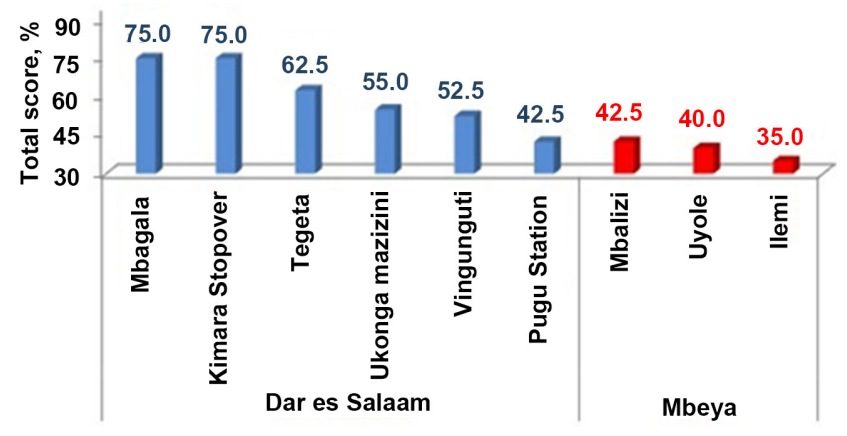

(c)

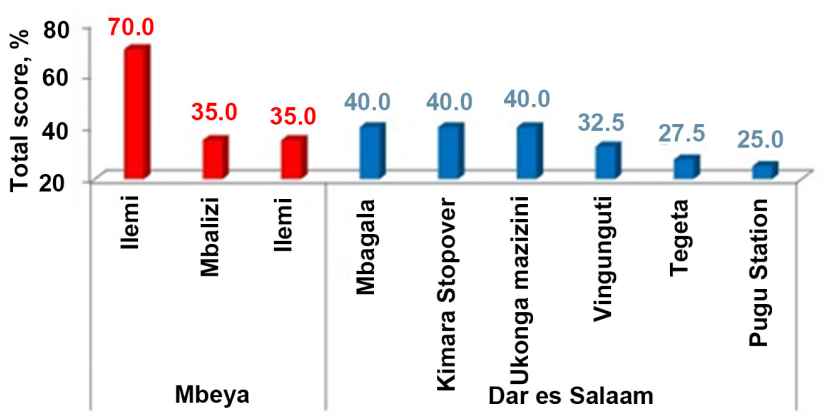

(b)

Figure 2. The scored points in percentage of beef quality impacting parameters in the vehicles assessed arranged according to the surveyed slaughtering facilities (a) painting in the slaughtering facilities; (b) labeling information; (c) degree of separateness of the carcasses carrying compartment; and (d) corrosion free carcasses contacting surfaces $(N=10$ in each slaughter facility).

evaluated vehicles as per painting ranged between $25 \%$ and $72.5 \%$ in which vehicles in Mbalizi, Mbagala, Kimara Stopover and Ukonga Mazizini were at the highest side as shown in Figure 2(a). Vehicles observed in Pugu Station, on the other hand, were the lowest compliant in terms of painting. Next, responses on the carcasses distributing vehicles based on labeling information as to whether it is marked "meat" or its respective translated Swahili word "Nyama" is presented in Figure 2(b). In this regards, Ilemi was observed to have the highest score (70\%), while Pugu station had $25.0 \%$ which was the lowest scored level. With regard to the degree of separateness of the carcasses carrying compartment summarized in Figure 2(c), the total score of the responses ranged between 75\% and $35 \%$. The compliance regarding this beef quality impacting parameter was high in Dar es Salaam (ranging between $42.5 \%$ and $75 \%$ ) compared to Mbeya (where the scores ranged from $42.5 \%$ to $35 \%$ only). In Dar es Salaam, the scored levels were lowest for Pugu Station, that is, $42.5 \%$. In connection to this, the carcasses distributing vehicles in Mbalizi, Uyole and Ilemi scored the lowest points among the vehicles in all facilities (that is, $42.5 \%, 40.0 \%$ and $35 \%$, respectively. Finally, assessment of corrosion resistance of carcasses contacting surfaces in the distributing vehicles was also presented in Figure 2(d). This quality impacting parameter was one of the lowest scored parameters observed in this study. During the assessment, it was observed that none of the facilities had vehicles that 
scored above $47.5 \%$ levels when compared to other factors or categories. Vingunguti, Ukonga Mazizini and Pugu station scored the lowest at 32.5\%, 30.0\% and $20 \%$ respectively.

With regard to carcasses transportation, the compliance was not good as most of the vehicles were not accepted as appropriate for beef transportation as it was shown in Figure 3. Contrary to the specification, the photographs indicate carcasses transporting vehicles taken in Mbeya city that are neither in white painting nor marked "meat" and or "Nyama".

The consequence of the non-compliance to the white painting in beef carrying compartment is beef deterioration due to heat infiltration that caused the raised of internal temperature caused by energy absorption to internal surfaces [6]. For, example, it was reported that low albedo compartment can have its internal temperature to above $50^{\circ} \mathrm{C}$ when external temperature reaches $25^{\circ} \mathrm{C}$. On the other hand, the consequences of non-adherence to labelling information, degree of separateness of the carcasses carrying compartment and corrosion resistant surfaces is contamination and bacteriological contamination [3].

Similar observations have been also reported in literature [5] [6], in which, besides the availability of meat transportation specification, the hired multipurpose motorbike and open vehicles were used without considering their respective hygienic status.

\subsection{Environmental Control on the Transported Carcasses}

Evaluation of environmental controls around the carcass distributing vehicles from the slaughtering facilities is presented in this study according to FAO standards on food quality. The results were summarized based on four main variables, i.e., heat proofing, refrigeration and temperature control, dust proofing and water tightness, that were assumed to be the key parameters to be monitored during carcasses transportation. The assessment results of beef carrying compartments specifically on the effect heat proofing characteristics of beef quality on the transported carcasses is presented in Figure 4(a). The evaluation scores of the distributing vehicles as per heat proofing in all the slaughtering facilities were at not more than 2.0 levels out of 10 as a maximum level. Acceptance of vehicles in Dar es Salaam was low with minimum of $0.5 \mathrm{lev}$ els in Pugu Station and maximum 2.0 levels in Mbagala and Kimara Stopover. It was also observed that, all vehicles in the slaughtering facilities in Mbeya were not acceptable as appropriate based on heat proofing receiving a zero assessment scoring levels. The consequence of poor adherence to this requirement include Carcasses carrying compartment should be designed in such a way that undesirable heat infiltration that might occur due to hot weather, sunny conditions, inadequate insulation and or air leakage is avoided [5]. Similarly, it was reported in literature that the level of compliance based on this parameter is low in developing world, where the marketing environment is characterized by smallholders whose respective operations are primarily comprised of informal distribution 

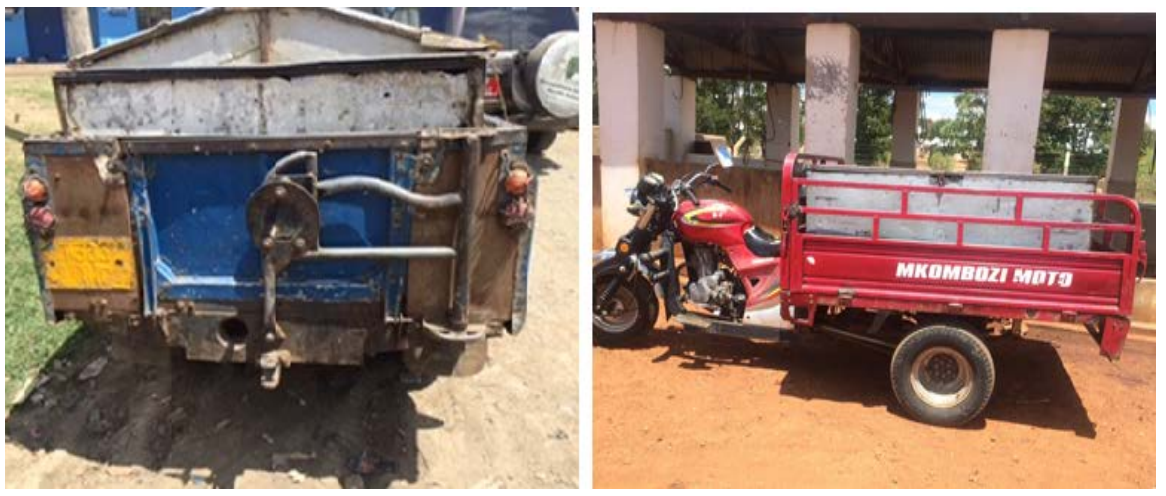

Figure 3. Photographs taken in Mbeya city indicating in-appropriate carcasses distributing vehicles.

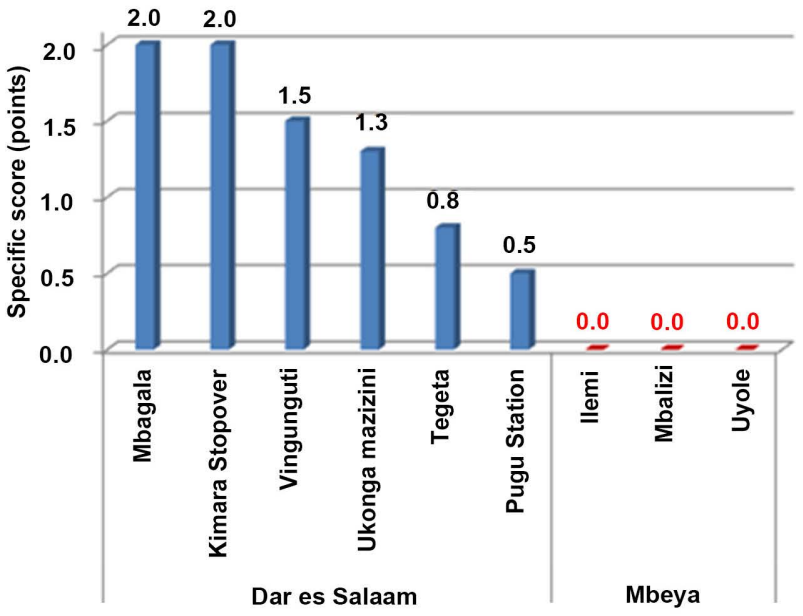

(a)

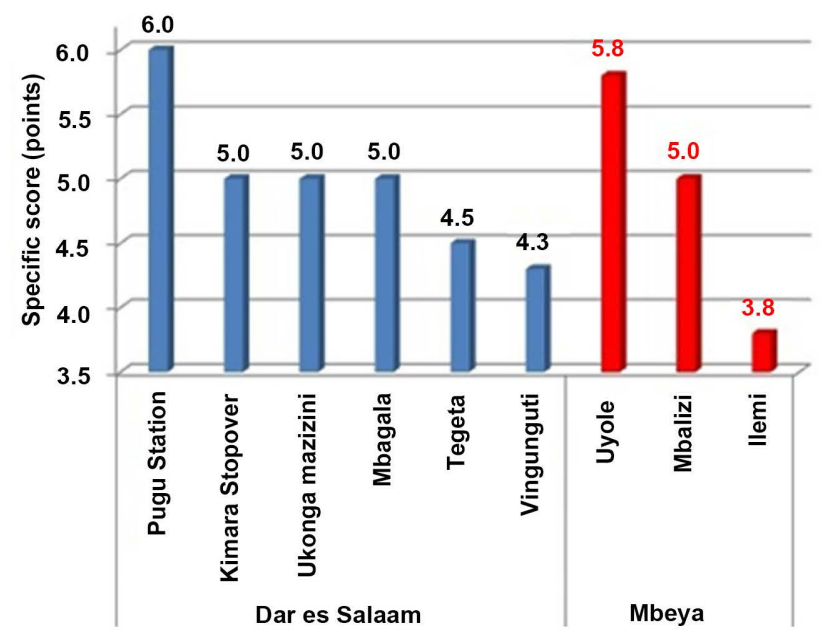

(c)

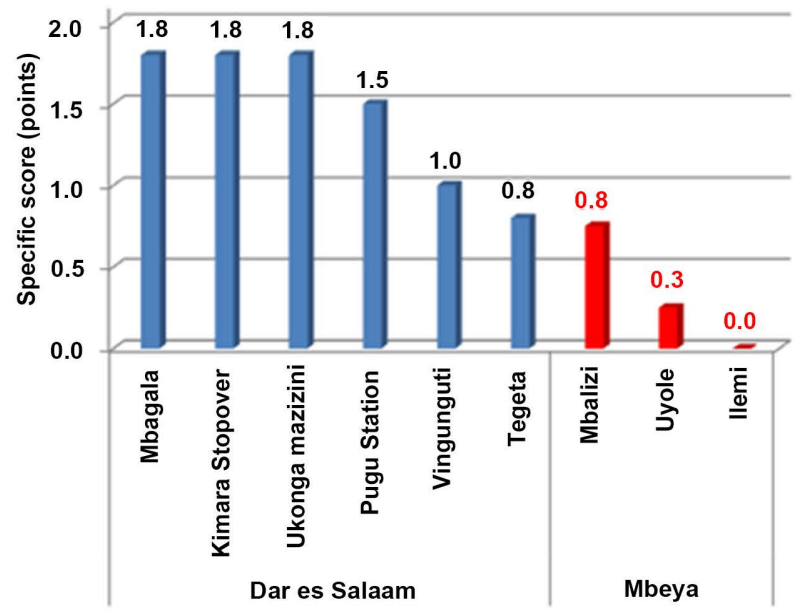

(b)

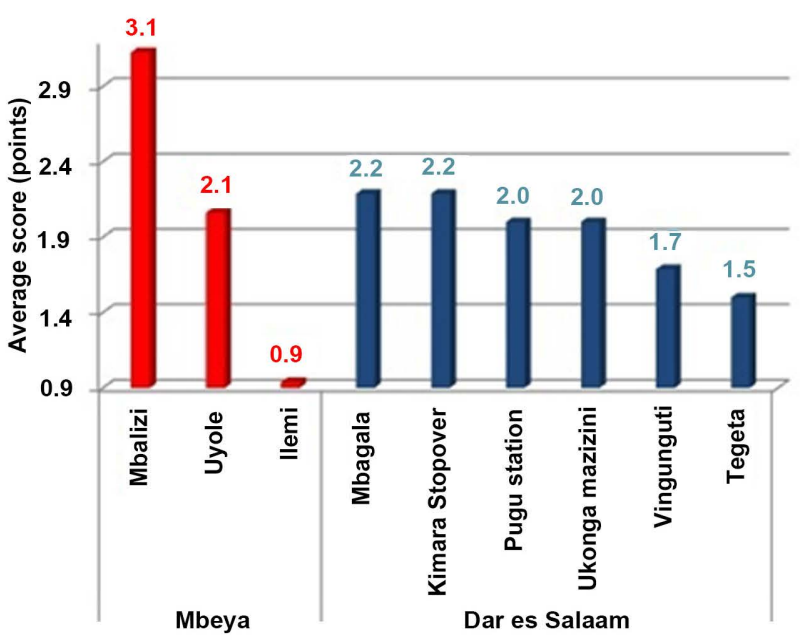

(d)

Figure 4. Evaluation results presented as specific scores based on carcasses distributing vehicles' characteristics as beef quality impacting parameter ( $N=10$ per facility). (a) Evaluation results for heat proofing characteristics of the carcasses carrying compartment; (b) Evaluation results for dust proofing characteristics of the carcasses carrying compartment; (c) Evaluation results for water tightness of characteristics of carcasses carrying compartment; (d) Evaluation results for on refrigeration and temperature control for carcasses carrying compartment. 
channels where safety and standards are either lacking or inadequately defined, and where they exist, are poorly adhered to.

Compliance of the designed carcasses carrying compartments based on dust proofing is also presented in Figure 4(b). The maximum score of the evaluated dust proofing in carcasses distribution based on the observation made in all facilities were at 1.8 levels out of 10. This level was observed in Dar es Salaam specifically at Mbagala, Kimara Stopover and Ukonga Mazizini. Furthermore, the compliance with respect to dust proofing parameter in this city that relatively observed to be higher than Mbeya where the ranged scores between 0.8 and zero levels. Vehicles in Mbalizi, on the other hand, scored 0.8 levels, the highest point among the other slaughtering facilities in Mbeya.

Figure 4(c) shows also the scores of water tightness as appropriate parameter in the designed beef carcasses transporting vehicles as observed in Mbeya and Dar es Salaam. This finding was measured based on 10 levels as it assumed that the designed beef carrying compartments were fully comply with the water tightness specifications. Carcasses distributing vehicles in Pugu Station in Dar es Salaam and Uyole in Mbeya scored the highest levels at 6.0 and 5.8, in their respective cities. On the other hand, the lowest levels scored in these cities were 4.3 and 3.8 Vingunguti in Dar es Salaam and Ilemi in Mbeya, respectively. These findings mark the ranges of 1.7 and 2.0 for the scored levels in Dar es Salaam and Mbeya, respectively. With exception to Tegeta (4.5), Vingunguti (4.3) and Ilemi (3.8), beef distributing vehicles in all facilities scored above the average with respect to this parameter. It was also observed as the highest scored parameter among the monitored variables in this study. Thus environmental controls in beef transportation are strongly adhered based on water tightness parameters specifically in Pugu Station and Uyole.

All the assessed carcasses distributing vehicles in the slaughtering facilities were not accepted as appropriate based on the temperature control and refrigeration as shown in Figure 4(d). With exception to Mbalizi, vehicles in all facilities scored less than 2.2 points out of 10 , signifies that strongly non-adherence to this parameter. Lack of this parameter in the designed carriers for meat distribution contributes to the spoilage of beef especially when the storage of carcasses is prolonged [3] [5]. However, this design parameter was noted as not necessary when the times spent for carcasses distribution were below the minimum durations required for refrigeration of the transported meat [4] [5]. It was further noted that the shortening of the time spent for carcasses distribution is manageable in many developing countries [3]. This is based on the fact that the slaughtering timetables were appropriately arranged enough for distributing vehicles to arrive at selling points too early to be staked in heavy traffic jams [3].

\subsection{Carcass Holding in the Compartment during Transportation}

Compartment for holding carcasses during transportation should be hygienically designed and equipped enough to prevent both meat from contacting the floor and entry of all sources of contamination. Assessment result of the carcass dis- 
tributing vehicles is presented based on the design characteristics based on holding facilities, hygiene status, availability edible offal carrying devices and water tightness of the devices under assumption that other beef quality impacting parameters are negligible. It was presented based on the specific scores in clustered columns that are arranged according to slaughtering facilities with maximum of 10 scored level when the surveyed facility is completely comply with specifications.

The highest and lowest scored facilities out of maximum 10 points with appropriate vans as per carcasses holding devices were Mbalizi (4.75) and Ilemi (0.75), respectively as shown in Figure 5(a). This was followed by Mbagala, Kimara Stopover and Ukonga Mazizini facilities that each of them had 4.25 scored value. Therefore, vehicles observed at Ilemi ( 0.75 out of 10$)$ were extremely not appropriate for beef distribution when compared to vehicles in other facilities. Similar observation on inappropriate carcass holding facilities in beef distributing vehicles have been reported in literature [4] [7], where the respective studies indicated the means in which piled carcasses were distributed by using inappropriate open trucks and motor bicycles

Figure 5(b) shows also specific scores of vehicles based on hygienic status as observed in slaughtering facilities in Mbeya and Dar es Salaam. Vehicles in Mbeya were observed to have higher scores in terms of hygiene status that ranged between 5.5 and 6.0 points as compared to Dar es Salaam that observed to have maximum score of 5.0 points and minimum of 2.75 points. While Ilemi facility in Mbeya was observed to have the highest scored levels (6.00 out of 10) in connection to the hygienic status of beef transporting vehicles, Vingunguti had the lowest (2.75 out of 10.0) among all the surveyed slaughtering facilities.

With exception to Vingunguti, The assessment results of the availability edible offal carrying containers in beef transporting vehicles indicated that the scored points in all the surveyed facilities in Dar es Salaam were between 4.5 and 4.5 levels as shown in Figure 6(c). The three lowest scored facilities with respect to the availability of edible offal carrying container in the beef distributing vehicles were Uyole (3.25), Vingunguti (3.0) and Ilemi (0.0).

Result of the evaluated water tightness in the edible offal's holding facilities found in the beef distributing vehicles was shown in Figure 5(d). Pugu station in Dar es Salaam and Uyole in Mbeya were the highest scored facilities at 6.0 and 5.75 levels, respectively. On the other hand, the scored points in Vingunguti and Ilemi of 4.25 and 3.75 levels, respectively, ranked these facilities to the lowest positions in their respective cities. Similar to this study, the non-compliance with this requirement is indicated in other studies [4] indicating that the piled carcasses being distributed to retailing shops by using open multipurpose vehicles.

\subsection{Characteristics of the Carcass Dispatching Area in the Slaughtering Facility}

All activities in the beef dispatching areas should be practiced based on the hygienic requirements. In connection to this, specific score with respect to 


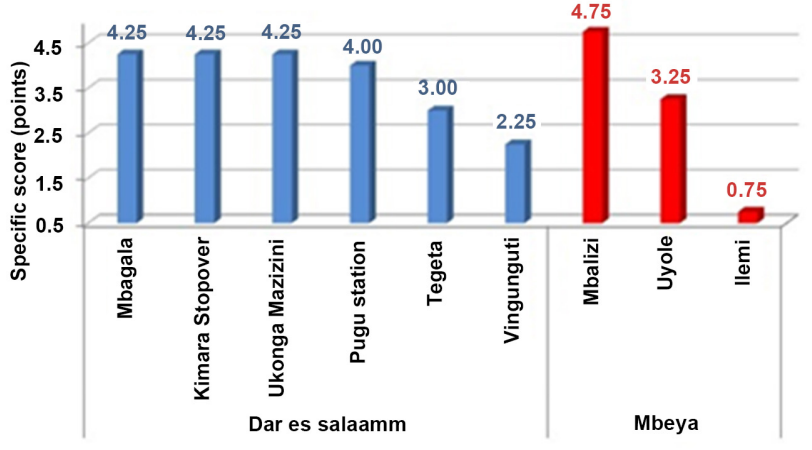

(a)

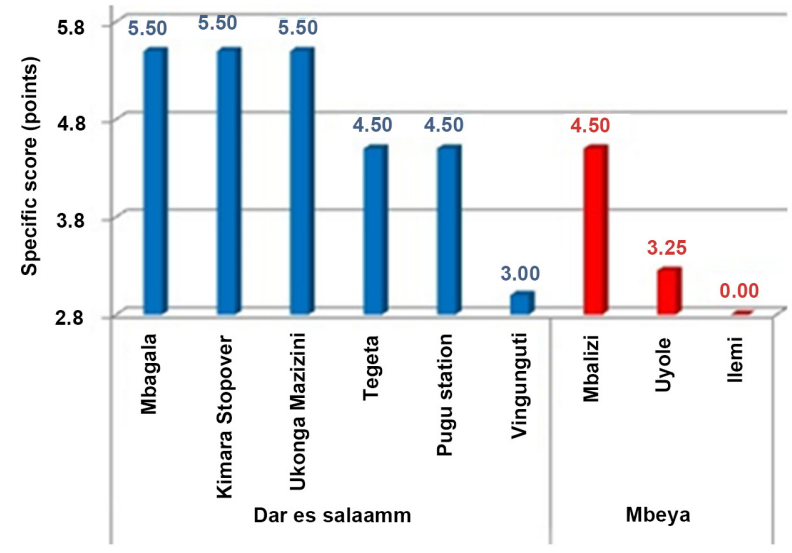

(c)

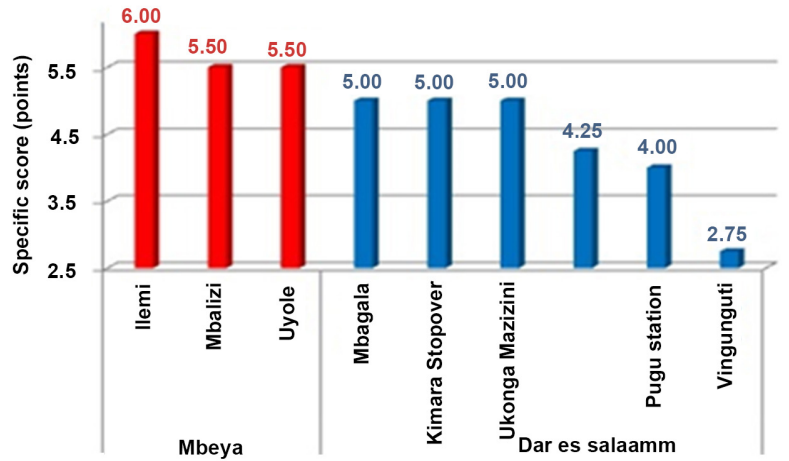

(b)

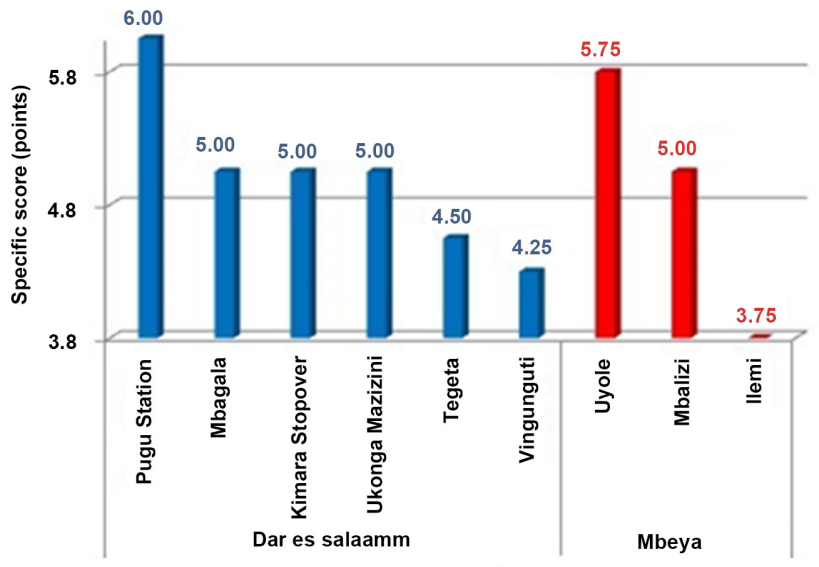

(d)

Figure 5. The specific scores of evaluated for carcas holding facilities and edible offal keeping facilities in the carcass distributing vehicles ( $N=10$ per facility). (a) Assessment of carcass holding facility in the distributing vehicles; (b) Assessment of hygiene status for the beef distributing vehicles; (c) Assessment of the availability of edible offal keeping facilities; (d) Assessment of water tightness for the edible offal keeping facilities.

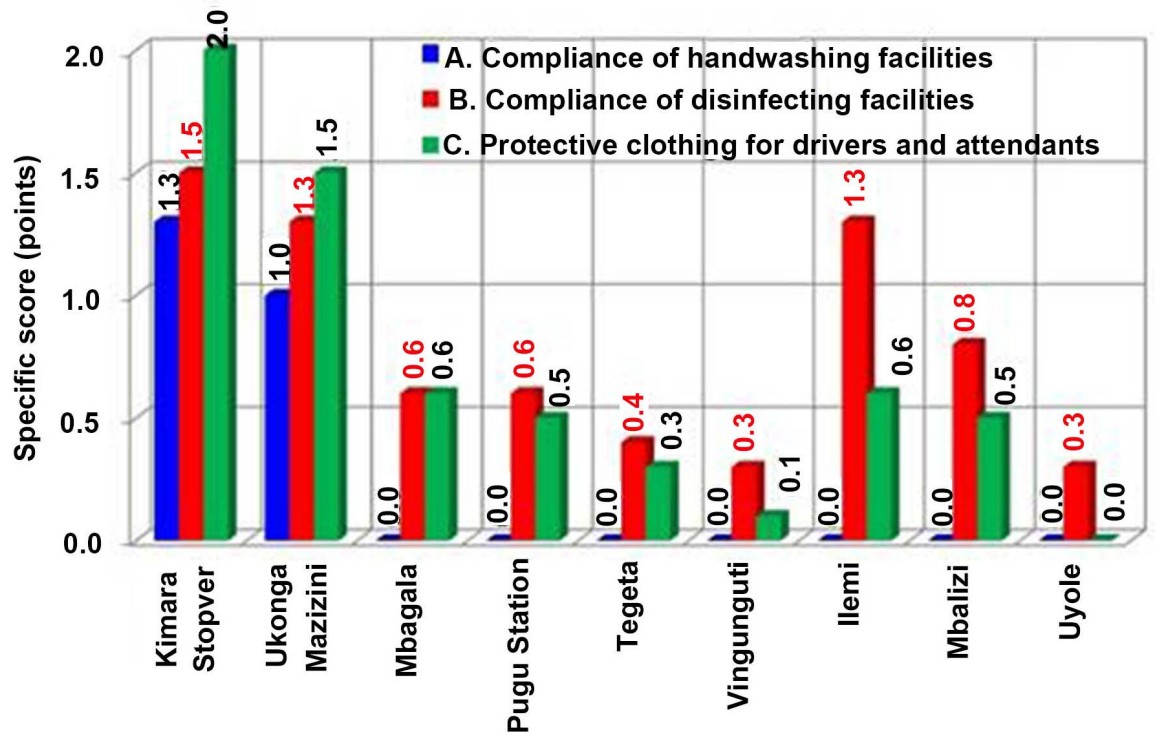

Figure 6. Compliance of carcass dispatching area within the slaughtering facility based on the assessed handwashing, disinfecting facilities and protective clothing for drivers and attendants ( $N=10$ per slaughtering facility). 
handwashing, sanitization and staff protective clothing in the carcass dispatching areas in the surveyed facilities at slaughtering facilities in Dar es Salaam and Mbeya is presented in this section. It is specific scores in clustered columns presented based on the surveyed slaughtering facilities with maximum of 10 scored levels under conditions that the facility meets the requirements. While Kimara Stopover and Ukonga Mazizini were the only facilities in which handwashing accessories were observed at 1.3 and 1.0 scored point, respectively, other facilities had zero scores as shown in Figure 6. This indicated that Mbagala, Vingunguti, Tegeta and Pugu, Ilemi, Mbailizi and Uyole facilities were not accepted as appropriated for dispatching carcass. This indicates possibilities of having high level of infection and microbiological contamination in the slaughtering facilities. With respect to sanitization in this area, Ukonga Mazizini was the highest scored facility at 1.5 point in the carcass dispatching area. This was followed by Mbagala and Mbalizi that each of them was scored 1.3 point, then Ilemi 0.8 scored point, before Pugu station and Kimara stopover each of them with 0.6 scored point. The lowest ranked in connection to sanitization were Vingunguti (0.4 point), Tegeta ( 0.3 point) and Uyole ( 0.3 point). It was also indicated that the assessed protective clothing for the drivers and the attendants, in the carcasses dispatching activities. Protective clothing has an impact on beef contamination. The highest ranked facilities were Ukonga Mazizini and Kimara Stopover in Dar es Salaam with scores of 2.0 and 1.5, respectively, and Uyole, Mbeya that scored only 0.6 . On the other hand, the lowest ranked facilities were Tegeta and Ilemi at 0.1 and 0.0 score level in Dar es Salaam and Mbeya, respectively. Based on this criterion all slaughter facilities did not qualify.

Similarly, former studies revealed the same scenarios, that is failure for meat handlers to adhere to the appropriate sanitation and hygienic practices like hand-washing, wearing of protective clothing and sanitization during meat distribution [4]. In addition to these studies, assessment of consumer preferences for quality and safety attributes indicated the means in which the meat/beef distributors in Addis Ababa, Ethiopia were not aware that working clothes and Uniforms are important beef quality impacting parameters.

\subsection{Sanitary and Hygienic Practices during Carcass Loading}

Sanitary and hygienic requirements should be adhered during loading of the carcasses in the distributing vehicles. The compliance of this requirement is presented based on the sanitary and hygienic practices in connection to the manner in which the meat carrying vehicles are operated. The acceptance based on sanitary and hygienic practices is presented based on the ways in which both meat and meat handlers are transported and if the engine was running during loading of meat as per food quality requirements. As sown in Figure 7(a) the highest three top ranked facilities in which vehicles appropriately accommodated the attendant during transportation were Ukonga Mazizini, Kimara Stopover and Ilemi at 2.5, 2.3 and 2.2 score levels, respectively. On the other hand, the lowest three ranked facilities were Mbagala, Mbalizi and Uyole that exhibit scored levels 


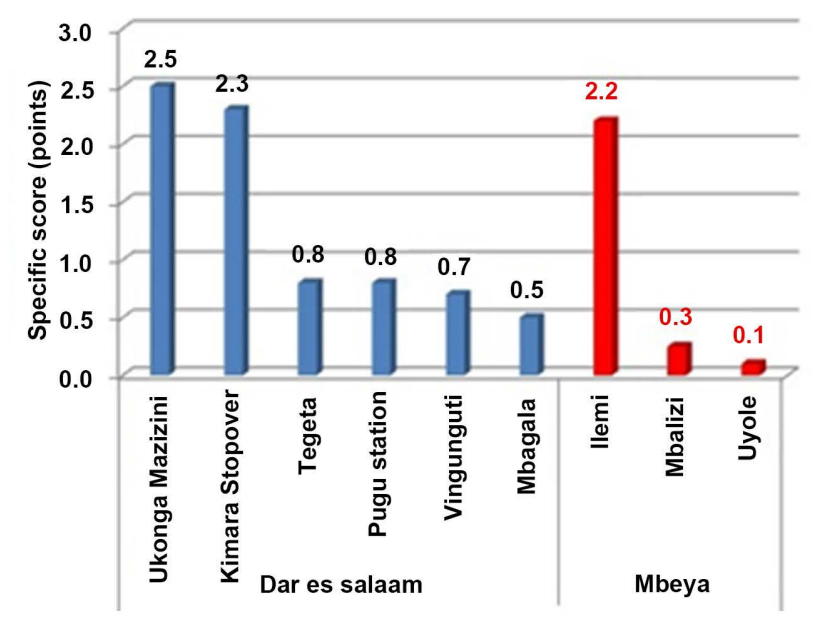

(a)

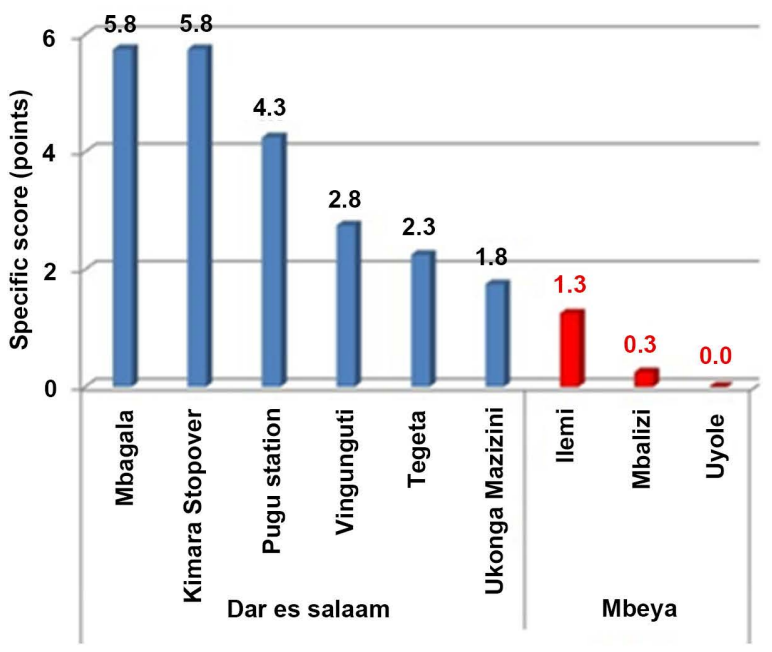

(b)

Figure 7. Compliance of of means of accommodating meat handlers in the carcass transporting vehicles and engine status as to whether running or not during loading of carcasses ( $N=10$ per slaughtering facility). (a) Compliance of means of accommodating meat handlers in the carcass transporting vehicles. (b) Compliance of engine status as to whether running or not during loading of carcasses.

of $0.5,0.3$ and 0.1 . The result presented in Figure 7(b) shows also that carcass transporting vehicles in Mbagala and Kimara stopover scored 5.8 point. The scored values in the rest of the surveyed facilities were below a half of 10, the value that could be obtained when the engine in of the assessed vehicles per facility could be off during the beef loading. It was also noted that, the lowest three most ranked facilities in descending order were Ilemi, Mbalizi and Uyole (all of which are in Mbeya).

Similar findings on the sanitary and hygiene practices were reported by other researchers [2] [3] [4] where meat handlers in Bawku Municipality in Ghana, Nairobi in Kenya, and Morogoro Municipality in Tanzania, were reported to practice inappropriate handling of beef during transportation. These findings indicate the means in which meat was loaded in distributing vehicles where in most cases handlers carried carcasses on shoulders and head using bare hands. This inappropriate handling of meat has been reported as one of major non-conformances against sanitary and hygienic practices as it accelerates the rate of contamination and spoilage of beef during transportation [3] [4] [25].

\subsection{Statistical Evaluation of the Compliance Data for the Beef Distributing Facilities}

The observed condition of beef distributing vehicles in slaughtering facilities was statistically analyzed based on their respective infrastructure conditions against raised hypotheses in connection to the established food quality specifications. The presentation includes analysis of the levels of their respective compliance and correlation of carcasses distributing vehicles located in different slaughtering facilities. The approach adopted for data presentation and analysis is in tandem with methods reported in literature reports [19] [20], for assessment of 
compliance with quality specifications. The analyzed results from the survey are presented in tables, clustered columns of total observed scores against expected scores and frequency distribution curves that were analyzed based on the established compliance index. The assessment of compliance index the meat transporting vehicles (adopted with modification [20] [21] was based on four compliance index levels: very weakly applied, weakly applied, semi strongly applied and strongly applied, having percentages of $20 \%-39 \%, 40 \%-49 \%, 50 \%-69 \%$ and $70 \%-100 \%$, respectively. The four compliance index levels are also categorized as A, B, C, and D, respectively. Results obtained for a total of 180 observations in the beef retailing premises in Mbeya and Dar es Salaam, are summarized in Table 2 and Figure 8.

In this study, the top most slaughtering facilities with vehicles that scored $34.4 \%$ and higher compliance indices in descending orders were Mbagala (34.4\%), Kimara Stopover (34.2\%), Ilomba (32.0\%) and Mbalizi (30.4\%). On the other hand, Ilemi was the lowest scored slaughtering facility at $26.7 \%$ compliance index. The total scored level for both cities was $29 \%$, the compliance index that deduced from $28 \%$ and $30 \%$ compliance indices scored from the surveyed butchers in Mbeya and Dar es Salaam.

The scored levels in Dar es Salaam ranged between 34.4\% and 23.9\% with Vingunguti being at the lowest side while Mbagala was revealed to be the highest scored slaughtering facility. On the other hand, the range in Mbeya was between $30.4 \%$ and $26.7 \%$, where Mbalizi being at the highest side, Ilemi at the other end. Figure 9(a) shows the distribution of the compliance indices in a superimposed plot that compares the compliance of the slaughtering facilities in Mbeya and

Table 2. Summary of compliance index of meat transporting vehicles that were categorized based on the surveyed slaughtering facilities $(N=10$ for Dar es Salaam and $N=29$ for Mbeya).

\begin{tabular}{|c|c|c|c|c|}
\hline City & $\begin{array}{l}\text { Slaughter facility in } \\
\text { which distributing } \\
\text { vehicle is found }\end{array}$ & $\begin{array}{c}\text { Compliance } \\
\text { index (\%) }\end{array}$ & Remarks & $\begin{array}{l}\text { Slaughtering } \\
\text { facilities }\end{array}$ \\
\hline \multirow{6}{*}{ Dar es Salaam } & Mbagala & 34.4 & Very weakly applied & Mbagala \\
\hline & Kimara Stopover & 34.2 & Very weakly applied & Kimara Stopover \\
\hline & Ukonga Mazizini & 31.8 & Very weakly applied & Ukonga Mazizini \\
\hline & Tegeta & 29.2 & Very weakly applied & Tegeta \\
\hline & Pugu Station & 24.2 & Very weakly applied & Pugu Station \\
\hline & Vingunguti & 23.9 & Very weakly applied & Vingunguti \\
\hline \multirow{3}{*}{ Mbeya } & Mbalizi & 30.4 & Very weakly applied & Mbalizi \\
\hline & Uyole & 28.3 & Very weakly applied & Uyole \\
\hline & Ilemi & 27 & Very weakly applied & Ilemi \\
\hline \multirow{3}{*}{ Total } & Dar es Salaam & 29.6 & Very weakly applied & Dar es Salaam \\
\hline & Mbeya & 28.5 & Very weakly applied & Mbeya \\
\hline & Both cities & 29.2 & Very weakly applied & Both cities \\
\hline
\end{tabular}




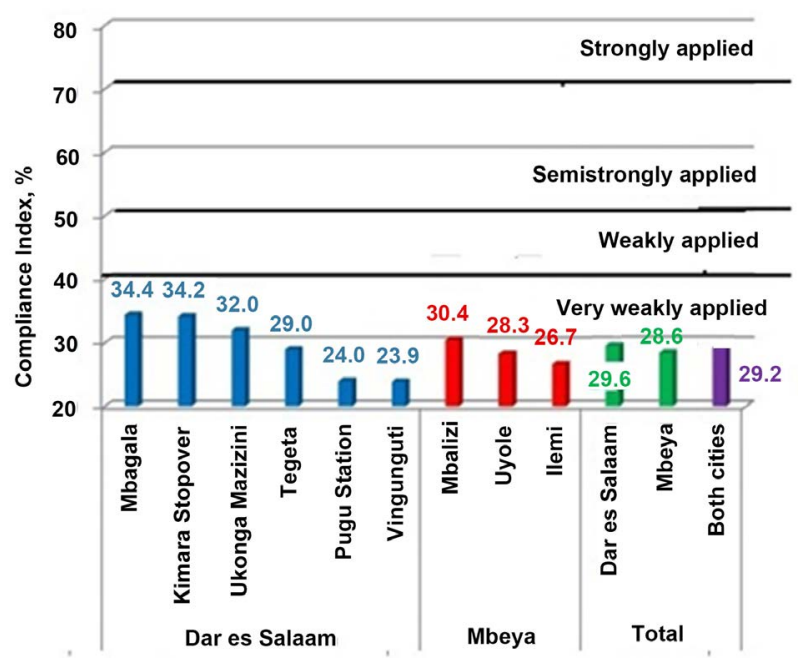

Figure 8. Compliance of the meat transporting vehicles in the surveyed slaughtering facilities in Dar es Salaam and Mbeya $(N$ $=6$ for Dar es Salaam and $N=3$ for Mbeya).

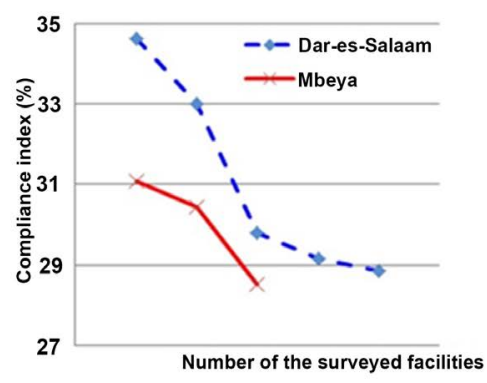

(a)

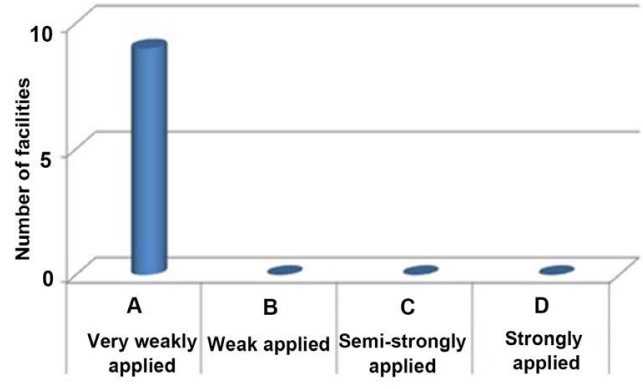

(b)

Figure 9. Superimposed plots of the compliance of the meat transporting vehicles and frequency distribution for meat transporting vehicles according to Likert scales $(N=6$ for Dar es Salaam and $N=3$ for Mbeya).

Dar es Salaam. It was noted that vehicles in two slaughtering facilities in Dar es Salaam were below 25\% that is Pugu station and Vingunguti. Furthermore, the level of compliance in Dar es Salaam shows scattered distribution between 35\% and $20 \%$ compliance indices. Whereas, the scored levels of most of the surveyed vehicles in slaughtering facilities in Mbeya were narrowed at the 25\% and 30\% compliance index range. In Figure 9(a), the distribution results were also presented based on the statistical comparison parameters. This includes frequency and cumulative frequency statistical parameters that were categorized based on four compliance index levels and named as A, B, C and D. The overall analysis of compliance frequency analysis results of the beef distributing vehicles in the surveyed slaughtering facility ( $N=10$ per slaughtering facility) can be summary as: none of the occurrences in other levels except level A (20\% - 39\%), which imply very weakly applied. Results based on these statistical parameters were further elaborated by using Frequency distribution plots as shown in Figure 9(b), which shows that the highest frequency was in category A at 20 - 39 compliance 
index level, i.e., the lowest scored categorized group.

The assessment of beef transporting facilities in the surveyed slaughtering facilities in connection to the first hypothesis of this study (Beef transporting vehicles complies with the specification), indicted very weakly compliance with the requirements. This can be interpreted that, the null hypothesis, that the carcasses distributing vehicles observed in the surveyed slaughtering facilities do not comply with the technical measures for food quality is accepted. The level of compliance observed from the test hypotheses were lower than that observed in other studies on compliance in developed countries [22]. This is explained based on the fact that incentives for beef production as per hygienic and safety requirements are higher in developed countries than in the developing world.

Table 3 presents analysis of variance (ANOVA) results covering beef quality impacting parameters with respect to activities and infrastructure in the surveyed slaughtering facilities. The table includes values of ss (sum of square), $\mathrm{df}$ (degree of freedom), ms (mean of squares), F (calculated statistical value), p-value (probability value) and $\mathrm{F}_{\text {crit }}$ (statistical value from statistical tables).

The count was established from the evaluated beef quality impacting parameters in vehicles at slaughtering facilities, leading to 18 . The sum on the other hand was established as a total of all scored points of the assessed parameters from each of the surveyed slaughtering facility leading to the values presented in the table. For, example for in Tegeta slaughtering facility, the count was 18 , leading to the sum of square 5.6 from assessed the scored values of the evaluated sections. In addition to that, the average (3.1) and variance (3.7) presented in the

Table 3. Analysis of Vvariance (ANOVA) results for equality of means between series based on 18 observations.

\begin{tabular}{ccccc}
\hline Groups & Count & Sum & Average & Variance \\
\hline Ilemi & 18 & 4.6 & 2.6 & 5.9 \\
Mbalizi & 18 & 5.0 & 2.8 & 5.7 \\
Uyole & 18 & 5.5 & 3.0 & 6.2 \\
Mbagala & 18 & 6.4 & 3.6 & 5.9 \\
Pugu station & 18 & 4.7 & 2.6 & 4.1 \\
Kimara Stopover & 18 & 6.3 & 3.5 & 6.0 \\
Tegeta & 18 & 5.6 & 3.1 & 3.7 \\
Ukonga & 18 & 5.4 & 3.0 & 5.2 \\
Vingunguti & 18 & 4.5 & 2.5 & 3.1 \\
ANOVA & & & & \\
Source of Variation & $S S$ & $8 f$ & MS & \\
Between Groups & 21.660 & 153 & 5.083 & \\
Within Groups & 777.743 & 161 & & \\
Total & 799.403 & & &
\end{tabular}


table were statistically deduced from the scored levels of all the assessed sections in Tegeta slaughtering facility. The same analysis was applied to vehicles in all other slaughtering facilities in Dar es Salaam and Mbeya. Since $p$ value is greater than 0.05 in both Mbeya and Dares Salaam we are accepting the null hypothesis and conclude that there is statistical no significant difference in compliance with food quality requirements in the assessed beef transporting vehicles in all surveyed slaughtering facilities.

\section{Conclusions}

While vehicles in Mbagala, Ukonga Mazizini, Kimara Stopover and Mbalizi were the highest scored facilities; vehicles in Pugu Station were the lowest ranked. The highest and lowest scored meat vans with respect to labeling specification were observed in Ilemi and Pugu Station, respectively. Results show that meat carrying vans observed in Dar es Salaam were more appropriate based on the degree of separateness of the carcasses carrying compartments compared to Mbeya. Corrosion free meat contacting surfaces was the lowest scored among the assessed parameters since none of the slaughtering facilities.

The highest and lowest scored levels out of 10 with respect to dust proofing was in Mbagala, Kimara Stopover and Ukonga Mazizini) and zero (Ilemi), respectively and noted as lowest parameter. The scored mark with respect to water tightness was not only above the average but also noted as the highest among all monitored variables, a situation that indicated strongly adherence to this parameter of environmental control. Vehicles in all the surveyed facilities with exception of Mbalizi were not accepted as appropriate for beef transportation in connection to temperature. The assessment results of vehicles at Ilemi in connection to the carcass holding devices during transportation indicated that they were extremely not appropriate for beef distribution. While Ilemi was observed to have the highest scored levels in connection to the hygienic status of beef transportation, Vingunguti was the lowest among all the surveyed slaughtering facilities.

The three lowest scored facilities with respect to the availability of edible offal carrying container in the beef distributing vehicles were Uyole, Vingunguti and Ilemi. While Pugu station and Uyole were the two highest scored facilities with respect to water tightness in offals' carrying containers, Vingunguti and Ilemi, respectively, were the lowest two ranked facilities. Whereas Kimara Stopover and Ukonga Mazizini were the only facilities with handwashing accessories, Mbagala, Vingunguti, Tegeta and Pugu, Ilemi, Mbailizi and Uyole facilities had zero scored indicating that they were absolutely not accepted as appropriated fcarcass dispatching area. With respect to sanitization, although Ukonga Mazizini was the highest scored among the assessed facilities, it is not accepted as appropriated for carcasses transportation.

The assessment results with respect to protective clothing for vehicles' staff indicated that Ukonga Mazizini and Kimara Stopover were the two highest ranked facilities, with too low scored points to accept that beef is appropriately 
transported. The scored values in the three highest ranked facilities in which vehicles were appropriately accommodated attendant during transportation were Ukonga Mazizini), Kimara Stopover and Ilemi were too low to conclude that beef in the surveyed cities is per hygienic specification. With exception to vehicles in Mbagala and Kimara, all the assessed facilities were below $50 \%$ for beef loading specification with respect to the engine status as to whether is running or switched off. The assessment of beef transporting facilities in connection to the first hypothesis of this study, indicted very weakly compliance with the requirements a situation that signifies that the vehicles do not comply with specification is accepted. Based on the fact that $\mathrm{p}$ value is greater than 0.05 in both cities, the null hypothesis was accepted and is concluded that there is statistical no significant difference in compliance with food quality requirements in the assessed beef transporting vehicles in Mbeya and Dar es Salaam.

\section{Conflicts of Interest}

The authors declare no conflicts of interest regarding the publication of this paper.

\section{References}

[1] Trent, N., Ormel, P., de Siles, J.L.G., Heinz, G. and James, M. (2003) The State of Meat Production in Developing Countries: 2002. In: Salem; D.J. and Rowan; A.N., Eds., The State of Animals II, Humane Society Press, 175-191.

[2] Adzitey, F., Teye, G.A. and Dinko, M.M. (2011) Pre and Post-Slaughter Animal Handling by Butchers in the Bawku Municipality of the Upper East Region of Ghana. Pakistan Veterinary Journal, 39, 177-184.

[3] Ntanga, P.D., Mdegela, R.H. and Nonga, H.E. (2014) Assessment of Beef Microbial Contamination at Abattoir and Retail Meat Shops in Morogoro Municipality, Tanzania. Tanzania Veterinary Journal, 29, 53-61.

[4] Chepkemoi, S., Lamuka, P.O., Abong, G.O. and Matofari, J. (2015) Sanitation and Hygiene Meat Handling Practices in Small and Medium Enterprise Butcheries in Kenya-Case Study of Nairobi and Isiolo Counties. Internet Journal of Food Safety, 17, 64-74.

[5] Koutsoumanis, K. and Taoukis, P.S. (2005) Meat Safety, Refrigerated Storage and Transport: Modeling and Management. Woodhead Publishing Ltd, Cambridge. https://doi.org/10.1201/9781439823521.ch23

[6] Lulietto, M.F., Sechi, P., Borgogni, E. and Cenci-Goga, B.T. (2016) Meat Spoilage: A Critical Review of a Neglected Alteration Due to Ropy Slime Producing Bacteria. Italian Journal of Animal Science, 14, 316-326.

[7] Adzitey, F. and Huda, N. (2011) Effect of Post-Slaughter Carcass Handling on Meat Quality. Pakistan Veterinary Journal, 32, 161-164.

[8] Zhou, G.H., Xu, X.L. and Liu, Y. (2010) Preservation Technologies for Fresh Meat (a Review). Meat Science, 86, 119-128. https://doi.org/10.1016/j.meatsci.2010.04.033

[9] Domaradzki, P., Skalecki, P., Florek, M. and Litwinczuk, A. (2011) Impact on Storage-Freezing Physical and Chemical Properties BEEF Vacuum-Packed, Nauka. Technologia Jakosc, 4, 117-126.

[10] Cegielska-Radziejewska, R., Kijowski, J., Nowak, E. and Zabielski, J. (2007) Effect of 
Tempeture on the Dynamics of Changes Number Bacteria in Selected Sausages Stored under Wholesale and Retail Trade. Nauka Technologia Jakosc, 4, 76-88.

[11] Czarniecka-Skubina, E. and Nowak, D. (2012) System Tracking and Tracing Food as Tool Ensure Consumer Safety. Zywnosc Nauka Technologia Jakosc, 5, 20-36.

[12] Bauman, H.E. (1995) The Origin and Concept of HACCP. Advances in Meat Research, 10, 1-7. https://doi.org/10.1007/978-1-4615-2149-5_1

[13] Priolo, F., Franzo, G., Pacifici, D. and Vinciguerra, V. (2001) Role of the Energy Transfer in the Optical Properties of Undoped and Er-Doped Interacting Si Nanocrystals. Journal of Applied Physics, 89, 264-272. https://doi.org/10.1063/1.1331074

[14] Gill, C.O. (1996) Extending the Storage Life of Meats. Meat Science, 43, 99-109. https://doi.org/10.1016/0309-1740(96)00058-7

[15] Niyonzima, E., Bora, D. and Ongol, M.P. (2013) Assessment of Beef Meat Microbial Contamination during Skinning, Dressing, Transportation and Marketing at a Commercial Abattoir in Kigali City, Rwanda. Pakistan Journal of Food Science, 23, 133-138.

[16] Noguera-Burbano, A., Quiñones-Medina, S., Mosquera-Sánchez, A., Vivas-Quila, N., Morales-Velasco, S., Muñoz-Quiceno, J. and Burkart, S. (2017) Post-Mortem Management and Microbiological Presence as Quality Factors along the Beef Value Chain in Colombia.

[17] Armitage, N.H. (1997) Use of Predictive Microbiology in Meat Hygiene Regulatory Activity. International Journal of Food Microbiology, 36, 103-109. https://doi.org/10.1016/S0168-1605(97)01261-0

[18] Gill, C.O. and Harrison, J.C.L. (1985) Evaluation of the Hygienic Efficiency of Offal Cooling Procedures. Food Microbiology, 2, 63-69. https://doi.org/10.1016/0740-0020(85)90024-3

[19] Siyanbola, A.A., Zaharadeen, A. and Adegboye, K. (2014) Assessment of Compliance with Disclosure Requirements of SAS 3 and IAS 16 by Listed Agricultural Firms in Nigeria. International Journal of Applied Research and Technology, 3, 117-129.

[20] Siyanbola, A.A., Musa, U.M. and Wula, T.J. (2014) An Assessment of Compliance with Disclosure Requirements of IAS 16 by Listed Agricultural Firms in Nigeria. International Journal of Economics, Business and Finance, 2, 1-16.

[21] Breccia, M., Latagliata, R., Stagno, F., Luciano, L., Gozzini, A., Castagnetti, F., Fava, C., Cavazzini, F., Annunziata, M., Russo, R.A., Pregno, P., Abruzzese, E., Vigneri, P., Rege-Cambrin, G., Sica, S., Pane, F., Santini, V., Specchia, G., Rosti, G. and Alimena, G. (2011) Charlson Comorbidity Index and Adult Comorbidity Evaluation-27 Scores Might Predict Treatment Compliance and Development of Pleural Effusions in Elderly Patients with Chronic Myeloid Leukemia Treated with SecondLine Dasatinib. Haematologica, 96, 1457-1461. https://doi.org/10.3324/haematol.2011.041251

[22] Henson, S. and Loader, R. (2001) Barriers to Agricultural Export from Developing Countries: The Role of Sanitary and Phytosanitary Requirements. World Development, 29, 85-102. https://doi.org/10.1016/S0305-750X(00)00085-1

[23] China, C.R. and Ndaro, M.S. (2016) A Review on Tanzanian Leather Value Chain Status. African Journal of Science and Research, 5, 55-60.

[24] Nandonde, S.W., Msuya, E. and Mtenga, L.A. (2013) Assessment of the Influence of Consumer Characteristics on the Choice of Beef Quality Attributes in Tanzania: An Experimental Economic Approach. Journal of Agricultural Economics and Development, 2, 111-119. 
[25] Rani, Z.T., Hugo, A., Hugo, C.J., Vimiso, P. and Muchenje, V. (2017) Effect of Post-Slaughter Handling during Distribution on Microbiological Quality and Safety of Meat in the Formal and Informal Sectors of South Africa: A Review. South African Journal of Animal Science, 47, 255-267. https://doi.org/10.4314/sajas.v47i3.2 